\title{
Adaptive Learning: A Stabilizing Influence Across Disciplines and Universities
}

\author{
Charles Dziuban, Patsy Moskal, Liza Parker, and Maria Campbell \\ University of Central Florida \\ Colm Howlin \\ Realizeit \\ Connie Johnson \\ Colorado Technical University
}

\begin{abstract}
This study represents an adaptive learning partnership among the University of Central Florida, Colorado Technical University, and the adaptive learning provider Realizeit. A 13-variable learning domain for students forms the basis of a component invariance study. The results show that four dimensions - knowledge acquisition, engagement activities, communication, and growth-remain constant in nursing and mathematics courses across the two universities, indicating that the adaptive modality stabilizes learning organization in multiple disciplines. The authors contend that similar collaborative partnerships among universities and vendors is an important next step in the research process.
\end{abstract}

Keywords: online courses, academic achievement, adaptive learning, blended learning, digital learning, college students, educational strategies

Dziuban, C., Howlin, C., Moskal, P., Johnson, C., Parker, L., \& Campbell, M. (2018). Adaptive learning: A stabilizing influence across disciplines and universities. Online Learning, 22(3), 7-39. doi:10.24059/olj.v22i3.1465

\section{Adaptive Learning: A Stabilizing Influence Across Disciplines and Universities}

Gelsinger (2018) recently commented on the impact of today's technology:

It may feel like the pace of technology disruption and change these days is so dizzying that it could not possibly get any more intense. Yet here's the science fact: the pace of change right now is the absolute slowest it will be for the rest of your life. Fasten your seatbelts. It's going to be a fascinating ride. (p. 7)

This quote emphasizes the growing impact of technology in higher education, including the emergence of predictive analytics, virtual and augmented reality, online and blended courses, flipped classrooms, and a recent innovation: technology-mediated adaptive learning (Johnson, 2017; Pugliese, 2016). These instructional technologies have important implications for the 
American educational system, but the potential for change in the adaptive learning process encompasses much of what has come before. Those technological developments may alter the teaching and learning process, but adaptive learning also modifies the most critical factor-time. Educators recognize that it takes some learners longer than others to understand a concept, develop a skill or demonstrate mastery. Students with the same motivation and ability levels require varying amounts of time to acquire knowledge. This is not only true between individual students but within individuals. Some of us might be able to acquire statistical concepts rapidly but take much longer with foreign language learning and vice versa (Thurstone, 1938; Gardner, 2011).

In 1963, John Carroll framed a model of the adaptive learning process with these statements:

Briefly, our model says that the learner will succeed in learning a given task to the extent that he spends the amount of time that he needs to learn the task.... First, spending time means actually spending time on the act of learning. "Time" is therefore not "elapsed time" but the time during which the person is oriented to the learning task and actively engaged in learning. (p. 2)

Educators understand the importance of nonequivalent learning time but have been constrained by the structure of the current educational system that most often sets a fixed learning time frame, making learning outcomes variable. But, if learning outcomes are held constant, then it follows that learning time will be the variable. Many current adaptive learning platforms that incorporate machine learning and decision-making provide a workable solution to the problem. There are other advantages embedded in these systems, including multiple learning paths, continual assessment incorporated into the instructional process, redirection to needed knowledge and skills, tailored instructional modalities, real-time instructor awareness of student status, and responsiveness to multiple learning behaviors. Most importantly for this study, these adaptive platform characteristics result in a wealth of data on the structural organization of learning, thereby enabling contextual comparisons.

The implications of this approach for teaching and learning impact every aspect of the educational process. First, adaptivity cedes much of the learning control to the student. In a truly adaptive course, students can negotiate their learning trajectory at a self-determined pace, in some cases finishing the requirements in a few days or weeks, or extending the semester past the scheduled end date. Dziuban, Howlin, Johnson, and Moskal (2017) confirm this by identifying several different successful behavior types in adaptive courses. For instance, the University of Central Florida finds a substantial cohort of students whose math placement score places them into intermediate algebra - a course that does not provide the necessary math credit but is a prerequisite to the for-credit college algebra. However, upon completing intermediate algebra in the adaptive modality, students may move to and complete college algebra in the same semester. On follow-up surveys, this led some students to ask, "Why do we need semesters?" This suggests that mathematics can be transformed into a well-planned set of contiguous skills rather than a group of courses. The same seems possible for most disciplines that have a hierarchical learning structure.

Adaptive learning alters the psychological learning contract between students and instructors - a feature of mutual understanding or misunderstanding that is vital to the learning process. The theory, originally developed by Argyris (1960), describes the implied relationship between employees and employers but has implications for the learning environment. These contracts consist of perceived obligations between students and instructors that are never expressly 
stated but become organic and subjective. However, they have well-defined components: voluntary choice, agreement, incompleteness, presence of numerous contract makers, plan for managing unsuccessful contract losses, and a relational model between student and teacher (Rousseau, 1990). In higher education, Dziuban, Moskal, Kramer, and Thompson (2013) demonstrate that violation of psychological contracts involves course rhythm, expectation rules, progression, engagement, and responsiveness. Students and instructors expect different things, leading to the potential for a toxic class environment. Adaptive learning, with clearly specified expectations and continuous assessment, eliminates most aspects of violated psychological contracts in education.

Faculty importance increases in the adaptive environment because they can identify learning objectives for students through course design and analytics data provided by the system. Instructors can suggest effective interaction and intervention with students in areas that require support or additional instruction. Faculty members have a real-time view of student progress that is not available in other methods of teaching. For instance, adaptive systems can reliably identify skills or concepts with which the class on average is excelling or having difficulty. In addition, instructors can track individual student progression through course content. This provides faculty the opportunity to modify their lecture, activities, or homework assignments in order to personalize instruction.

The characteristics of adaptive learning comprise a complex learning system that exhibits properties surpassing other instructional technologies. Page (2010) summarizes the phenomenon this way:

Complex systems are collections of diverse, connected, interdependent entities whose behavior is determined by rules, which may adapt, but need not. The interactions of these entities often produce phenomena that are more than the parts. These phenomena are called emergent. Given this characterization, the brain would count as a complex system, so would a rainforest, and so would the city of Baltimore. Each contains diverse, connected entities that interact. (pp. 6-7)

This study seeks to understand the emergent properties of adaptive learning by identifying the latent dimensions underlying the process in courses across multiple disciplines and two structurally different universities. The objective is to determine if differing disciplines and university contexts alter learning patterns, thereby impacting effectiveness across diverse landscapes. However, this study not only involves the two universities but also the adaptive learning provider (Realizeit) in a working partnership that capitalizes on the strength of each organization. This is a study of the adaptive learning process and not the platform. In this paper, we will argue that these working partnerships, independent of marketing pressures, are essential and that those organizations that are called (we hope historically) vendors are becoming a vital part of the what Floridi (2014) terms e-ducation, where learning is continually delocalized, uniform, and global, and the real challenge is not what to teach but how to teach.

\section{Background on Adaptive Learning}

Adaptive learning's resurgence is due, in part, to modern computing technologies that manage large datasets and run machine learning algorithms quickly and efficiently. The concept is not new (Carroll, 1963), but more sophisticated online platforms make it increasingly viable as an instructional modality. Educators and researchers are investigating the use of this technology 
in part due to an increase in performance metrics and funding that ties to the continuing need to improve student success and retention.

Adaptive learning acts like a GPS for students. As they progress through the course content, it allows for personalized instruction while altering their pathways through course objectives. It continually assesses their knowledge, helping them efficiently and effectively progress through the course (Moskal, Carter, \& Johnson, 2017). This ability to allow students to either advance or remediate is one of the reasons adaptive learning is being investigated for its potential for mastery learning (Bienkowski, Feng, \& Means, 2012; Dziuban, 2017). The enthusiasm is likely to continue, with several national reports pointing to adaptive learning as one of the important and influential developments in education (Becker et al., 2017; Legon \& Garrett, 2018; Office of Educational Technology, 2017).

Vendor platforms vary widely in support, content, and adaptivity, as the adaptive choices continue to grow (Brown, 2015; Tyton Partners, 2016). Content-agnostic platforms provide the faculty or institution with control over the structure and logic of the system, as well as the ability to develop content from the ground up. While faculty often prefer this level of control over course content and assessment, platforms with built-in courses provide quicker and easier solutions but often are limited with respect to modification. The opportunity cost associated with expedited application is that educators have minimal ability to customize the content or assessment with these courseware options when compared to content-agnostic platforms. Many off-the-shelf courseware choices involve general education courses or other offerings that may be similar in content across many higher education institutions (Brown, 2015; Tyton Partners, 2016). In response to faculty requests for more control, platforms are providing some ability to change or modify aspects of the system. Similarly, vendors offering those adaptive platforms on the contentagnostic end of the spectrum recognize the need to help faculty who may want to expedite their course development. Vendors may provide instructional design support when their adaptive courseware has significant authoring capabilities and facilitates the importing of existing courses or open educational resources to alleviate some of the course design burden for faculty. Research indicates this workload and change in technology can increase faculty reluctance to engage in adaptive learning (Betts \& Heaston, 2014). Increased support and training can help ameliorate faculty hesitation (Wingo, Ivankova, \& Moss, 2017), especially when combined with release time and training for them (Kennedy, 2015). Institutional support is necessary for successful implementation of any instructional technology, including adaptive learning (Buchanan, Sainter, \& Saunders, 2013; Dziuban, Moskal, \& Hartman, 2016; Bastedo \& Cavanagh, 2016; Pugliese, 2016; Johnson \& Zone, in review).

Several national initiatives provide funding for investigating adaptive courseware's potential in higher education (Bill and Melinda Gates Foundation, 2014; Association of Public \& Land-Grant Universities, 2016; Online Learning Consortium, 2016), and while some preliminary results have been positive, much more work is necessary. Varied campus climates and adaptive courseware implementations can make comparisons and generalizability of findings difficult, thereby making the research to date not nearly as prolific or promising as hoped.

\section{Adaptive Learning's Impact on Student Learning and Attitudes}

A meta-analysis conducted by SRI researchers Yarnall, Means, and Wetzel (2016) reports on findings from institutions receiving funding through the Bill \& Melinda Gates Foundation Adaptive Learning Market Acceleration Program (ALMAP). The grant provides support to 14 
higher education institutions to investigate the use of adaptive courseware for improved outcomes for low-income students in 15 key gateway general education and seven developmental education courses. Nine adaptive products were used in 23 courses from summer 2013 to winter 2015. This study combined the institutions' research results, including data on 19,500 students and 280 instructors. Overall, results were mixed, with researchers finding no significant impact on grades for most of the courses and with slightly higher outcomes for four out of the 15 implementation sites. In general, adaptive learning did not improve students' odds of successful course completion. The report identifies challenges impacting the research, including the variety of designs and platforms across the many institutions, making comparisons indeterminate, at best.

A case study funded by the Bill \& Melinda Gates Foundation and conducted by the Boston Consulting Group and Arizona State University (Bailey et al., 2018) reports on several universities that have found gains in student success in courses utilizing adaptive learning. Georgia State University found a decrease in DFW rates for minority and Pell-eligible students in introductory writing courses. Arizona State University found positive outcomes in biology where students had a $2 \%$ increase in success (ABC grade) in adaptive mixed-modality courses compared to traditional mixed-modality courses. When controlling across assessments and faculty, investigators found even greater gains. Results in college algebra were highest in traditional, (nonadaptive), face-toface courses, although adaptive mixed-modality showed $11 \%$ higher success rates than comparable, nonadaptive, mixed-modality courses.

Colorado Technical University achieved gains in pass rates for Trigonometry (from 76\% to $94 \%$ ) and a decrease in course withdrawal rates (from $36 \%$ to $17 \%$ ) by incorporating adaptive learning into traditional instruction. They found similar gains in student success in Calculus with pass rates increasing from $66 \%$ to $94 \%$ and withdrawal rates decreasing from $45 \%$ to $13 \%$. In addition, students performed better in the next math sequence course, Calculus, when adaptive learning was utilized in the prerequisite math courses (Daines, Troka, \& Santiago, 2016).

The extensiveness of learning analytics data available as a student progresses through adaptive learning content allows for more granularity in identifying changes to their level of content knowledge. Researchers identified the ability to identify at-risk students early (Dziuban, Moskal, Cassisi, \& Fawcett, 2016) and more precise measurement of learning that expedites mastery, improves course outcomes, and ultimately leads to increased student retention (Nakic, Granic, \& Glavinic, 2015; Alli, Rajan, \& Ratliff, 2016; Smith, 2013).

Students respond positively about the use of adaptive learning, finding it blends seamlessly with their online course components. As an instructional tool, personalization is found by students to be key to helping them learn the course material while increasing engagement (Dziuban, Moskal, Cassisi, \& Fawcett, 2016). These findings appear to be independent of university contexts, indicating that students see the value of adaptive learning and are positive about engaging with this instructional method (Dziuban, Howlin, Johnson, \& Moskal, 2017; Dziuban, Moskal, Johnson, \& Evans, 2017).

\section{Study Purpose}

This study sought to identify the underlying learning dimensions (components) for students in an adaptive educational environment across different disciplines in two organizationally and structurally diverse universities that serve considerably different student populations. The findings have implications for the fields of learning science and predictive analytics by identifying the viability of constructed variables that reduce the problem of the small predictive power of 
individual measures and the complexity of incorporating their interactions. This area of inquiry has a long history in many scientific areas: for example, in education by identifying the elements of learning quality (Quality Matters, 2014); in psychology's development of the Big Five personality characteristics (Tupes \& Christal, 1992; Goldberg, 1992); in cultural anthropology's identification of the necessary characteristics for animal domestication (Diamond, 2005); and the standard model in quantum physics (Kibble, 2015). Although the methods for identifying fundamental components in these fields vary, the objective is the same-find a robust theory that frames better understanding. However, such an undertaking must address questions that fall into three categories before proceeding to the operational phase of development:

1. Are the components common and independent across discipline and institution?

2. Are the components disparate and contextually specific to disciplines and institutions?

3. Are there some partial patterns of communality that depend on discipline and institution? An affirmative answer to the first question enables the possibility of an operational study. However, answering yes to questions two and three makes future development much more complicated, reducing the possibility of a common solution.

\section{The University Partnership}

\section{Methods}

\section{Colorado Technical University}

Colorado Technical University (CTU) began operation in 1965. In 2000, CTU offered online programs for the first time, and the university now offers over 50 core academic programsfrom associate to doctorate - that are delivered fully online or in a blended format at the two campuses located in Colorado. Currently, the student population is approximately 25,000.

CTU's mission is to provide industry-relevant higher education to a diverse student population through innovative technology and experienced faculty, enabling the pursuit of personal and professional goals. Programs are offered in career-focused disciplines, including engineering, computer science, health sciences, business and management, criminal justice, and information technology.

CTU serves a diverse population, and the average age for online students is 36 , with female students accounting for $60 \%$ of the population. CTU is an open enrollment institution, and students enter CTU with varying levels of academic and professional experience in addition to transfer credit.

Due to the diversity of the needs of a nontraditional, open enrollment student population, CTU began piloting adaptive learning in 2012. Those pilots began with implementing adaptive learning in three general education courses, including two math courses and one English course. Approximately 100 students were involved with the initial pilots in these three first-year courses, traditionally seen as courses that are barriers to student success.

\section{The University of Central Florida}

As one of the 12 public universities in Florida's state university system, the University of Central Florida (UCF) is a metropolitan research institution serving over 66,000 students with an average age of 24 (UCF, n.d.-b). Digital learning is strategically used at UCF to increase 
educational access for students, and the university offered its first online course in 1996 . Over $42 \%$ of student credit hours are in online and blended courses. The majority of students take a variety of course modalities, with $81 \%$ of students taking at least one online or blended course and $72 \%$ at least one fully online course in the 2016-2017 academic year. Online and blended learning accounts for the majority of UCF's enrollment growth and the Center for Distributed Learning (CDL) provides both faculty and student support for these courses (Center for Distributed Learning Division of Digital Learning, n.d.).

In 2014, UCF began investigating the use of adaptive learning as an instructional technology for faculty to use. Its promise of personalized instruction was attractive for the potential to improve student success in key courses. After vendor demonstrations and discussions and with faculty input, Realizeit was chosen as the enterprise platform for adaptive learning. Its adaptivity and customization were important to faculty who wanted to control the content of their courses. Three faculty volunteered to participate in the pilot, and in fall 2014 the first adaptive learning courses went live with two courses: General Psychology and Pathophysiology, with 154 students enrolled in both courses (College Algebra followed in spring 2015). The use of adaptive learning in online and blended courses is supported through the university distributed learning student fee as established by Florida statute (UCF, 2012).

Creating adaptive learning courses is time-consuming. To help facilitate faculty adoption, CDL established a team of instructional designers to support personalized adaptive learning (PAL). Adaptive learning faculty are required to complete a faculty development program (PAL6000). The PAL team currently consists of four instructional designers (IDs) who are "fluent" in Realizeit and work with faculty during PAL6000 to help them understand the features of the adaptive platform system while creating pedagogically sound courses (Chen, Bastedo, Kirkley, Stull, \& Tojo, 2017). The IDs are assigned to faculty for the duration of the course administration. In addition, the CDL has graphic artists, a video team, and programmers who support faculty as they design their online instructional components and teach the digital learning courses (UCF, n.d.-a.).

After numerous discussions at scientific meetings, UCF and CTU began discussing how to collaborate on joint adaptive learning research. Although the universities are very different, both utilize Realizeit as their enterprise solution for adaptive learning, and joint research across the varying institutional demographics has helped inform the research and development of adaptive learning in instruction. Table 1 illustrates the status of Realizeit adoption at both CTU and UCF.

Table 1.

Adaptive Learning at UCF and CTU*

\begin{tabular}{|c|c|c|}
\hline & $\begin{array}{l}\text { UNIVERSITY OF } \\
\text { UCF CENTRAL FLORIDA }\end{array}$ & .11 \\
\hline Started with adaptive learning & Fall 2014 & Fall 2012 \\
\hline Number of adaptive courses & 22 (66 instances) & 254 (3,597 instances) \\
\hline Typical course length & $\begin{array}{l}12 \text { weeks (summer) or } 15 \\
\text { weeks (fall or spring) }\end{array}$ & 5.5 weeks \\
\hline Number of students & 3,325 & 122,194 \\
\hline Number of enrollments in courses & 3,842 & 838,363 \\
\hline Enrollments per student & 1.2 & 6.9 \\
\hline
\end{tabular}

*Data provided by Realizeit; correct as of May 16, 2018 


\section{Courses Used in the Study}

Both CTU and UCF have a variety of courses offered in adaptive learning. For this paper, we attempted to make comparisons across courses of similar disciplines, namely math and nursing. Table 2 provides the description of each course provided in the university course catalogs and the number of sections and students included.

Table 2.

\section{UCF and CTU Courses Used for Comparison}

\begin{tabular}{|c|c|c|c|}
\hline UCF course & Description & $\begin{array}{c}\text { Number of } \\
\text { sections }\end{array}$ & $\begin{array}{l}\text { Number of } \\
\text { students }\end{array}$ \\
\hline Intermediate Algebra & $\begin{array}{l}\text { This course is designed to reinforce and } \\
\text { develop algebra skills, including rational } \\
\text { expressions, radicals, linear and quadratic } \\
\text { equations, linear inequalities, and } \\
\text { applications. }\end{array}$ & 2 & 332 \\
\hline College Algebra & $\begin{array}{l}\text { This course is designed to teach students } \\
\text { about high-degree polynomials, graphs, } \\
\text { systems of equations, and different types } \\
\text { of functions. }\end{array}$ & 5 & 363 \\
\hline Pathophysiology & $\begin{array}{l}\text { This course is designed to teach students } \\
\text { abnormalities in physiologic functioning } \\
\text { of the human body. }\end{array}$ & 9 & 537 \\
\hline CTU course & Description & $\begin{array}{c}\text { Number of } \\
\text { sections }\end{array}$ & $\begin{array}{c}\text { Number of } \\
\text { students }\end{array}$ \\
\hline $\begin{array}{c}\text { Introduction to } \\
\text { Algebra }\end{array}$ & $\begin{array}{l}\text { Students learn how to use symbols for } \\
\text { numbers, basic transformations of } \\
\text { algebraic expressions, linear relationships } \\
\text { of real-life quantities, and solving } \\
\text { quadratic equations. }\end{array}$ & 38 & 6,693 \\
\hline $\begin{array}{c}\text { Analytic College } \\
\text { Algebra }\end{array}$ & $\begin{array}{l}\text { Students review basic algebra and } \\
\text { continue to rational and radical } \\
\text { expressions, functions, computation with } \\
\text { complex numbers, and solving systems of } \\
\text { linear equations with matrices and } \\
\text { determinants. }\end{array}$ & 26 & 4,486 \\
\hline $\begin{array}{c}\text { Trends in } \\
\text { Contemporary Nursing }\end{array}$ & $\begin{array}{l}\text { This course will prepare nurses for roles } \\
\text { that can effectively respond to all the } \\
\text { changes and challenges facing today's } \\
\text { health care environment; this includes } \\
\text { completing a change management project. }\end{array}$ & 30 & 303 \\
\hline
\end{tabular}

\section{The Adaptive Learning Platform}

The principle underlying Realizeit is to separate curriculum from content. Students encounter a substantiality increased cognitive load in any learning environment where they must navigate a curriculum and select content. The system alleviates this issue with its Adaptive Intelligence Engine (AIE), a collection of structures, algorithms, and processes that help bridge the gap between the curriculum, content, and the learner. 
Within the platform, the interaction of the learner with both the curriculum and the content generates a comprehensive stream of data that powers the algorithmic adaptivity, personalization, guidance, and feedback. The more valid the information in the models becomes, the more it improves adaptation and personalization (Vandewaetere \& Clarebout, 2014).

\section{Curriculum \& Content}

Traditionally, a curriculum is defined by a hierarchical structure with the individual concepts to be learned at the base of the structure. Realizeit supplements this with a second level, known as the Curriculum Prerequisite Network - an acyclic graph where the nodes represent the concepts to be learned and the edges represent the prerequisite relationships that exist between them.

Just as an instructor can teach the same concept in many ways, Realizeit allows multiple pieces of content and resources to be available for each concept in the curriculum. The design is content agnostic - it is applicable in any learning domain and can deliver learning content in multiple formats.

\section{Adaptive Intelligence Engine}

The AIE is responsible for discovering and adapting to each individual learner's changing achievement, behavior, and preferences following a loop structure described in VanLehn (2006) and du Boulay (2006). They propose that adaptive systems be built upon an outer loop that decides which task the student should do next and an inner loop that organizes steps within a task. A third loop surrounds the first two levels and is required to establish model student learning parameters. The third loop in the model is responsible for learning from the student data set. These algorithms supply information across the loops, enabling them to function effectively based on the most upto-date data.

At the core of Realizeit, the AIE is a probabilistic model using Bayesian estimation procedures with the instructor-created curriculum prerequisite network (Howlin \& Lynch, 2014). The Bayesian procedure incorporates students' initial baseline results to estimate their prior knowledge. As students progress through their adaptive courses, additional outcomes enable Realizeit to suggest alternative learning trajectories. This results in continuous updates of students' ability estimates, the knowledge they have acquired, objectives that still require mastery, and recommendations for optimal paths through the course material.

\section{Adaptivity}

Students will experience learning adaptivity and personalization customized by several different mechanisms. These include the following:

- Tailoring their start position on an objective by determining which concepts they have mastered.

- Based on their behavior, attainment, performance, and progress, dynamically altering their pathway through the curriculum, including revision and practice exercises, in real time.

- Selecting the most suitable content for them as they undertake a course module, given their learning requirement at that time.

- Selecting the most appropriate pedagogical elements within a concept or objective.

- Adapting learning paths based on rules specified by the instructors or the students themselves. 
Within Realizeit, the main source of adaptivity originates from the intelligence engine discussed above; however, personalization may be customized by the instructor or the students themselves.

At almost every point in the learning process, the student has final control over learning and next steps within the system. They may alter their learning path progression (trying new concepts) and alternatively undertake review (revising/practicing previous concepts). In addition, they have access to supplemental learning material, including adding, removing, and reordering course elements within the content. However, this is not a completely open landscape for students but is structured for optimal learning while allowing for flexibility. Guidance is provided by the Realizeit system that directs students toward ability-appropriate activities to increase the potential for success.

\section{Data and metrics}

\section{Results}

From the array of metrics collected by Realizeit, a small subset of key performance aggregate indicators becomes available for review within the system and may be exported to other analysis platforms. Thirteen of these metrics became the basis of this study and are detailed in Table 3.

Table 3.

Explanation of Variables

\begin{tabular}{|c|c|}
\hline Variable & Explanation \\
\hline Knowledge State (KS) & $\begin{array}{l}\text { A measure of student ability. The mean level of mastery that } \\
\text { the students have shown on topics they have studied. }\end{array}$ \\
\hline Knowledge Covered (KC) & $\begin{array}{l}\text { A measure of student progress. The mean completion state of } \\
\text { each of the course objectives. }\end{array}$ \\
\hline Calculated (CA) & $\begin{array}{l}\text { An institution-defined combination of several metrics, mainly } \\
\mathrm{KS} \text { and } \mathrm{KC} \text {, used to assign a grade to students. }\end{array}$ \\
\hline Average Score (AS) & $\begin{array}{l}\text { The mean result across all learning, revision, practice, and } \\
\text { assessment activities. }\end{array}$ \\
\hline Determine Knowledge (DK) & $\begin{array}{l}\text { The percentage objectives on which the student completed a } \\
\text { Determine Knowledge operation. }\end{array}$ \\
\hline Knowledge State Growth (KSG) & $\begin{array}{l}\text { The extent by which a student's KS has changed from the start } \\
\text { of the course. Can be positive, negative, or zero. }\end{array}$ \\
\hline Knowledge Covered Growth (KCG) & $\begin{array}{l}\text { The extent by which a student's KC has changed from the } \\
\text { start of the course. Can be positive or zero. }\end{array}$ \\
\hline Interactions (IN) & $\begin{array}{l}\text { The engagement level of the instructor(s) with the student. } \\
\text { The total number of interactions. }\end{array}$ \\
\hline Messages Sent (MS) & $\begin{array}{l}\text { The number of the interactions sent by the instructor that were } \\
\text { simple messages. }\end{array}$ \\
\hline Total Activities (TA) & $\begin{array}{l}\text { The total number of nonassessment activities started by the } \\
\text { student. }\end{array}$ \\
\hline Total Time (TT) & $\begin{array}{l}\text { The total time spent on nonassessment activities started by the } \\
\text { student. }\end{array}$ \\
\hline Number Revise (NR) & $\begin{array}{l}\text { The total number of node-level activities that are classified as } \\
\text { revision. }\end{array}$ \\
\hline Number Practice (NP) & The total number of objective-level practice activities. \\
\hline
\end{tabular}




\section{Principal Component Analysis}

The thirteen variables describing students' cognitive outcomes and behaviors from the Realizeit platform for each of the three courses from UCF, the three courses from CTU, and combined samples for each institution are intercorrelated and subjected to the principal component procedure (Mulaik, 2009). The method approximates common factor analysis by explaining the variance and relationships (correlations) among the indices and reducing the data set to a smaller dimensionality. We chose principal components for this study because the Realizeit measures were not psychometrically derived but, rather, comprise markers of student achievement and behavior and are relatively independent of each other. Principal components analysis answers the question, "Are we able to explain the correlations we have in hand by reducing them to a smaller number of common constructed variables simplifying the observed relationships?" The procedure involves a direct eigenvalue-eigenvector decomposition of the correlation matrix within the variable space and avoids the indeterminacy of common factor models. In practice, however, principal components yield a reasonably close approximation to common factor results. Components were retained for interpretation according to the eigenvalues of the correlation matrices greater than one (Kaiser \& Rice, 1974), with retained components transformed (rotated) using the Promax procedure (Hendrickson \& White, 1964). Component pattern coefficients with an absolute value greater than .40 form interpretation salience.

Operationally, the study involves six separate and two combined component solutions. This analysis addresses the invariance aspect of the study - that is, whether the cognitive organization of adaptive learning is constant or whether the patterns change by institution or course context. To address this, the 28 possible pairwise comparisons of the eight component solutions were examined. For each comparison, the similarity between component and total component solutions was measured using the Tucker congruence coefficient (Chan, Ho, Leung, Chan, \& Yung, 1999). Analogous to the Pearson correlation, the value of the coefficient ranges from 1 (perfect congruence) to -1 (perfect inverse relationship), with 0 indicating no linear association between the two components. The pattern matrices were first subjected to the Procrustes rotation (Schönemann, 1966), ensuring maximum alignment between components. Several subsets of the 28 possible comparisons are presented and discussed here; however, the similarity metrics for the remaining comparisons are available in Appendix A. We will start by examining if the cognitive organization of adaptive learning within institutions is constant across the courses considered in this study and then examine the cross-institutional cognitive organization. The subset of comparisons used include the following:

- Internal Institutional Comparisons-comparing component solutions across samples within an institution
- UCF
○ CTU

- Cross-Institutional Comparisons - comparing component solution from samples across institutions

- Entire samples

- Course level

- Comparison of the four algebra courses

- Comparison of the two nursing courses 
Discussion surrounding the interpretation of the Tucker congruence coefficients (Chan, Ho, Leung, Chan, \& Yung, 1999) focuses on the value that one can consider indicating that two components are equivalent. A summary of the possible thresholds, along with the results from a study on the interpretation of the coefficients by experts, can be found in Lorenzo-Seva and ten Berge, (2006). Values of $0.80,0.85$, and 0.90 have been used extensively to declare components equal, with Tucker providing the following guidelines: 0.98 to $1.00=$ excellent, 0.92 to $0.98=$ good, 0.82 to $0.92=$ borderline, 0.68 to $0.82=$ poor, and below $0.68=$ terrible. From their research on expert interpretation, Lorenzo-Seva and ten Berge (2006) recommended that values between 0.85 and 0.94 be considered fair and that any components with a value higher than 0.95 be considered equal. In our analysis, we use this stricter level of guidance.

However, the reader should be cognizant that these recommendations for interpretation are still somewhat arbitrary. They are rules of thumb that may prove helpful, but they are not absolute standards. While we have used a pattern coefficient salience of .4 as the cutoff, this could have been .3 or .5 . Both sets of coefficients, because they are blind to the labels of the values and components, provide objective indicators of similarity and relevance. However, they do not supplant reflective interpretation and judgement. Those aspects of critical thinking remain, as they should, at the discretion of the authors and readers. These solutions are never completely clear-cut or free from the impact of interpretation.

\section{Foreshadowing the Results}

Because this study involves a complex course and university comparison, the study design requires eight separate component matrices, six similarity coefficient tables, and one similarity table (found in Appendix A). Therefore, a preliminary summary of the findings will help the reader navigate the data. Referring to the three questions posed in the Study Purpose section that we need to address before proceeding to the operational phase of development, we find that we can answer the first question in the affirmative: the components are common and independent across discipline and institution. With only minor variations, the same four principal components emerge within and across courses and universities. The components are clearly defined, exhibiting good approximation to simple structure. Visual inspection and the computed similarity values confirm strong correspondence among similarly named dimensions. To facilitate understanding of the four components we present a shorthand notation rubric for them. The components are fully explained in the conclusion of these results, but their notation and name are common to all tables that follow.

Knowledge Acquisition (KA) indicates a cluster of variables that indexes the degree to which students achieved mastery in the course nodes and modules. This component always appeared first and accounted for the largest proportion of variance.

Engagement Activities (EA) correlates with variables that measure to what degree students actively participate in their courses. This component always appears second because of the moderately diminished variance that can be attributed to it.

Growth $(G)$ loads on variables that measure the change in knowledge acquisition. This component is clear but at times was either the third or fourth component to emerge.

Communication $(C)$ is the interaction component and relates to the social learning aspect of adaptive learning. Like $\mathrm{G}$, it tends to alternate between the third and fourth positions. 


\section{Internal Institutional Comparisons: UCF}

The component pattern matrices for samples from the UCF courses Intermediate Algebra, College Algebra, and Pathophysiology are given in Table 4, Table 5, and Table 6, respectively. The four extracted components from the Intermediate Algebra sample pattern solution have associated eigenvalues of $4.0,3.0,1.8$, and 1.2 , and these four components capture $76.9 \%$ of the variance found in the original 13 variables. For College Algebra, the eigenvalues are 4.5, 2.1, 2.0, and 1.4 , again capturing $76.9 \%$ of the variance, and for Pathophysiology, the eigenvalues are 3.8, $2.7,1.7$, and 1.1 , capturing $75.1 \%$ of the variance. All three solutions have a low absolute average correlation between the components, with values of $0.27,0.23$, and 0.12 for Intermediate Algebra, College Algebra, and Pathophysiology, respectively.

Table 4

Transformed (Promax) Pattern Matrix for the Realizeit Indices, Intermediate Algebra at UCF $(n=332)$

\begin{tabular}{|c|c|c|c|c|}
\hline \multirow[t]{2}{*}{ Item } & \multicolumn{4}{|c|}{ Components } \\
\hline & KA & EA & G & $\mathrm{C}$ \\
\hline Calculated & .94 & .07 & .09 & -.03 \\
\hline Knowledge state & .94 & .02 & .05 & -.12 \\
\hline Knowledge covered & .93 & .02 & .11 & .07 \\
\hline Determine knowledge & .75 & -.17 & -.17 & .16 \\
\hline Average score & .42 & .08 & -.10 & -.13 \\
\hline Total activities & -.03 & .90 & .10 & .11 \\
\hline Num. revised & .00 & .90 & -.05 & -.05 \\
\hline Total time & -.09 & .75 & .18 & .05 \\
\hline Num. practiced & .13 & .71 & -.32 & -.06 \\
\hline Knowledge state growth & -.05 & .04 & .95 & -.08 \\
\hline Knowledge covered growth & .04 & -.06 & .95 & .06 \\
\hline Messages sent & .00 & .03 & -.01 & .98 \\
\hline Interactions & .00 & .03 & -.01 & .98 \\
\hline
\end{tabular}

Table 5

Transformed (Promax) Pattern Matrix for the Realizeit Indices, College Algebra at UCF $(n=363)$

\begin{tabular}{|c|c|c|c|c|}
\hline \multirow[t]{2}{*}{ Item } & \multicolumn{4}{|c|}{ Components } \\
\hline & KA & EA & $\mathrm{C}$ & $\mathrm{G}$ \\
\hline Knowledge state & .95 & -.12 & -.04 & .07 \\
\hline Calculated & .94 & .03 & -.01 & .08 \\
\hline Knowledge covered & .91 & .08 & .01 & .06 \\
\hline Average score & .67 & -.09 & -.12 & -.33 \\
\hline Determine knowledge & .58 & .19 & .20 & -.03 \\
\hline Total activities & .01 & .95 & .02 & .04 \\
\hline Num. revised & .02 & .88 & .03 & -.02 \\
\hline Num. practiced & -.02 & .76 & -.02 & -.20 \\
\hline Total time & -.01 & .44 & -.17 & .39 \\
\hline Interactions & -.01 & -.01 & .99 & .00 \\
\hline Messages sent & -.01 & -.01 & .99 & .00 \\
\hline Knowledge state growth & -.20 & -.04 & .00 & .94 \\
\hline Knowledge covered growth & .20 & -.11 & .04 & .84 \\
\hline
\end{tabular}


Table 6

Transformed (Promax) Pattern Matrix for the Realizeit Indices, Pathophysiology at UCF $(n=537)$

\begin{tabular}{lrrrr}
\hline Item & \multicolumn{4}{c}{ Components } \\
& KA & EA & G & C \\
\hline Knowledge covered & $\mathbf{. 9 7}$ & -.01 & .12 & .01 \\
Calculated & $\mathbf{. 9 6}$ & .05 & .09 & -.05 \\
Knowledge state & $\mathbf{. 9 2}$ & .08 & .06 & -.11 \\
Determine knowledge & $\mathbf{. 7 9}$ & -.24 & -.26 & .13 \\
Total activities & -.04 & .97 & .00 & -.02 \\
Num. revised & -.03 & $\mathbf{. 9 4}$ & .02 & -.06 \\
Total time & -.04 &. $\mathbf{7 2}$ & .08 & .08 \\
Knowledge covered growth & .09 & .02 & $\mathbf{. 9 4}$ & .10 \\
Knowledge state growth & .01 & .15 & $\mathbf{. 9 1}$ & .02 \\
Num. practiced & .14 & .31 & $\mathbf{- . 5 5}$ & .14 \\
Interactions & .01 & .05 & .00 & $\mathbf{. 9 6}$ \\
Messages sent & .00 & .05 & .00 & $\mathbf{. 9 6}$ \\
Average score & .09 & .27 & -.18 & $\mathbf{- . 4 1}$ \\
\hline
\end{tabular}

Preliminary examination of the pattern matrices yields some insights. First, each variable loads on a single component, simplifying the interpretation. Second, there is some slight variation in which variables load onto each of the components and the strength of that loading across the solutions, although on inspection there is some degree of consistency. This suggests that the level of variance in the component solutions should be small. Finally, in some cases, there is a swapping of position in similar components. Comparing Intermediate Algebra and College Algebra, components $\mathrm{G}$ and $\mathrm{C}$ swap positions.

As previously stated, the Tucker congruence coefficient (Chan et al., 1999) provides a means to compare both individual components and total patterns to measure the similarity of solutions derived from principal component analysis on the same set of variables from two samples. The congruence between the individual components for each solution for the UCF courses is provided in Table 7.

\section{Table 7}

Similarity Matrices at the Component Level for Three UCF Courses

\begin{tabular}{cccccc}
\hline & & \multicolumn{4}{c}{ Pathophysiology } \\
& & KA & \multicolumn{1}{c}{ EA } & \multicolumn{1}{l}{ G } & \multicolumn{1}{l}{ C } \\
\hline \multirow{4}{*}{ College } & KA & $\mathbf{. 9 3}$ & .05 & .00 & -.13 \\
Algebra & EA & .05 & $\mathbf{. 8 6}$ & -.23 & .05 \\
& $\mathrm{C}$ & .05 & -.03 & .00 & $\mathbf{. 9 5}$ \\
& $\mathrm{G}$ & .07 & .15 & $\mathbf{. 9 2}$ & .11 \\
\hline & $\mathrm{KA}$ & $\mathbf{. 9 8}$ & .00 & -.04 & -.08 \\
Intermediate & $\mathrm{EA}$ & -.01 & $\mathbf{. 9 6}$ & -.12 & .03 \\
Algebra & $\mathrm{G}$ & .05 & .11 & $\mathbf{. 9 8}$ & .04 \\
& $\mathrm{C}$ & .02 & .03 & .00 & $\mathbf{. 9 6}$ \\
\hline
\end{tabular}

\begin{tabular}{cccc}
\hline \multicolumn{4}{c}{ Intermediate Algebra } \\
KA & EA & \multicolumn{1}{c}{ G } & \multicolumn{1}{c}{ C } \\
\hline .98 & .01 & .03 & -.02 \\
.04 & .94 & -.12 & .03 \\
.03 & -.04 & -.01 & .98 \\
-.02 & .06 & .96 & .02 \\
\hline
\end{tabular}


For the courses Intermediate Algebra and Pathophysiology, the highest level of similarity is along the main diagonal. That is, the first components from each course are most like each other, the second components are most like each other, and so on for all four dimensions. We use the term alignment to describe this matching of solutions. Using the Lorenzo-Seva and ten Berge (2006) guidelines, all components in each solution can be considered equal to their aligned component in the other solution. All other similarity values are close to zero. In other words, we can consider the two component solutions to be equal. This is confirmed by the measure of overall similarity, the total Tucker congruence coefficient, which for these two solutions is 0.97 .

We see similarly high levels of similarity between the component solutions of College Algebra and Intermediate Algebra. The swapping of components $\mathrm{C}$ and $\mathrm{G}$, which we discovered from examining the pattern matrices directly, becomes obvious. While the highest similarity values for each component in a solution are not found in the corresponding position in the other solution, we can still consider these two solutions to be aligned, as all components in one solution align with a single component in the other solution. The levels of similarity between the aligned components is again above the 0.94 threshold of Lorenzo-Seva and ten Berge (2006), which allows them to be considered equal. Calculation of the total Tucker congruence coefficient needed to take the positions of aligned components into account but yielded a high value of 0.97 .

The final comparison is between College Algebra and Pathophysiology. Again, we see the swapping of the position of components, but the component solutions still align with each other. Here, three of the components fall slightly below the threshold to be considered equal but are still considered to be fair. The total Tucker congruence coefficient is 0.92 . So, while not equal like the other solutions, the high similarity values can allow us to treat these two solutions as approximately equal.

\section{Internal Institutional Comparisons: CTU}

The component pattern matrices for samples from the CTU courses Introduction to Algebra, Analytic Algebra, and Trends in Contemporary Nursing are given in Table 8, Table 9, and Table 10, respectively. The components from the Introduction to Algebra sample pattern solution have associated eigenvalues of $3.3,2.4,1.7$, and 1.5, capturing $68.5 \%$ of the variance. For Analytic Algebra, the eigenvalues are $3.5,2.3,1.6$, and 1.4 , capturing $67.7 \%$ of the variance, and for Trends in Contemporary Nursing, the eigenvalues are $3.5,2.4,1.7$, and 1.2 , capturing $67.7 \%$ of the variance. The percentages of variance explained by the component solutions for the CTU courses are slightly lower than that explained by the component solutions for UCF courses. All three CTU course-level solutions have a low absolute average correlation between the components' values of $0.08,0.16$, and 0.10 for Introduction to Algebra, Analytic Algebra, and Trends in Contemporary Nursing, respectively.

Preliminary examinations of these pattern matrices reveal some differences and similarities to those observed in the UCF pattern matrices. For example, for the Analytic Algebra components, each variable does not neatly load on to a single component. Knowledge Covered Growth and Num. Practiced both load on components EA and G. As with the UCF patterns, there is some variation in which variables load onto each of the components across the samples. Finally, there is no swapping of position in similar components across solutions.

The congruence between the individual components for each sample from the CTU courses is given in Table 11. For all three comparisons, the components align along the main diagonal, with values off the main diagonal in each matrix close to zero. As with the UCF components, this provides a simple mapping from a single component in one solution to a single component in another. This main diagonal also makes evident that there is no swapping of positions in the aligned components. 
Table 8

Transformed (Promax) Pattern Matrix for the Realizeit Indices, Introduction to Algebra at CTU $(n=6,993)$

\begin{tabular}{lrrrr}
\hline Item & \multicolumn{4}{c}{ Components } \\
& KA & \multicolumn{1}{c}{ EA } & \multicolumn{1}{c}{ C } & \multicolumn{1}{c}{$\mathrm{G}$} \\
\hline Calculated & $\mathbf{. 9 6}$ & .09 & -.02 & -.02 \\
Knowledge state & $\mathbf{. 8 9}$ & -.17 & -.03 & .04 \\
Average score & $\mathbf{. 8 8}$ & -.12 & -.02 & .04 \\
Knowledge covered & $\mathbf{. 7 5}$ & .21 & .03 & -.04 \\
Total activities & -.04 & $\mathbf{. 9 2}$ & -.03 & .05 \\
Num. revised & -.03 & $\mathbf{. 8 2}$ & -.10 & .04 \\
Total time & -.01 & $\mathbf{. 7 3}$ & -.01 & .10 \\
Num. practiced & .08 & $\mathbf{. 5 1}$ & .11 & -.27 \\
Messages sent & .05 & -.10 & $\mathbf{. 9 2}$ & .04 \\
Interactions & -.11 & .03 & $\mathbf{. 9 0}$ & .00 \\
Knowledge state growth & .15 & -.01 & .05 & $\mathbf{. 8 2}$ \\
Knowledge covered growth & .01 & .19 & .12 & $\mathbf{. 7 3}$ \\
Determine knowledge & .18 & .15 & .15 & $\mathbf{- . 6 0}$ \\
\hline
\end{tabular}

Table 9

Transformed (Promax) Pattern Matrix for the Realizeit Indices, Analytic Algebra at CTU $(n=4,486)$

\begin{tabular}{lrrrr}
\hline Item & \multicolumn{4}{c}{ Components } \\
& KA & \multicolumn{1}{c}{ EA } & \multicolumn{1}{c}{ C } & \multicolumn{1}{c}{$\mathrm{G}$} \\
\hline Calculated & $\mathbf{. 9 5}$ & .11 & .01 & -.07 \\
Average score & $\mathbf{. 9 2}$ & -.13 & .00 & .08 \\
Knowledge state & $\mathbf{. 8 9}$ & -.21 & -.06 & -.01 \\
Knowledge covered & $\mathbf{. 8 1}$ & .22 & .07 & -.08 \\
Total activities & -.06 & $\mathbf{. 9 3}$ & .00 & -.03 \\
Num. revised & -.01 & $\mathbf{. 8 1}$ & -.02 & -.09 \\
Total time & .01 & $\mathbf{. 6 3}$ & -.06 & .17 \\
Interactions & -.04 & .08 & $\mathbf{. 9 0}$ & -.01 \\
Messages sent & .06 & -.14 & $\mathbf{. 8 8}$ & .05 \\
Knowledge state growth & -.10 & .00 & -.06 & $\mathbf{. 7 6}$ \\
Knowledge covered growth & .13 & $\mathbf{4 0}$ & .01 & $\mathbf{. 6 9}$ \\
Num. practiced & -.06 & $\mathbf{. 4 4}$ & .07 & $\mathbf{- . 4 7}$ \\
Determine knowledge & .10 & .06 & -.22 & $\mathbf{- . 4 4}$ \\
\hline
\end{tabular}


Table 10

Transformed (Promax) Pattern Matrix for the Realizeit Indices, Trends in Contemporary Nursing at CTU $(n=303)$

\begin{tabular}{lcrrr}
\hline Item & \multicolumn{4}{c}{ Components } \\
& KA & \multicolumn{1}{c}{ EA } & \multicolumn{1}{c}{ C } & \multicolumn{1}{c}{ G } \\
\hline Knowledge state & $\mathbf{. 9 5}$ & .02 & .05 & -.07 \\
Average score & $\mathbf{. 8 9}$ & -.12 & -.02 & -.04 \\
Calculated & $\mathbf{. 8}$ & .16 & .02 & .13 \\
Total activities & -.02 & $\mathbf{. 9 4}$ & .05 & .04 \\
Num. revised & .12 & $\mathbf{. 8 3}$ & -.05 & -.02 \\
Total time & -.05 &. $\mathbf{7 5}$ & .04 & -.15 \\
Num. practiced & -.14 & $\mathbf{. 4 1}$ & .35 & $\mathbf{. 4 1}$ \\
Interactions & .00 & .00 & $\mathbf{. 9 6}$ & -.12 \\
Messages sent & .05 & .01 & $\mathbf{. 9 4}$ & -.08 \\
Determine knowledge & -.08 & .16 & -.28 & $\mathbf{. 6 5}$ \\
Knowledge covered growth & -.18 & .33 & -.08 & $\mathbf{- . 6 5}$ \\
Knowledge state growth & .13 & .36 & -.12 & $\mathbf{- . 5 3}$ \\
Knowledge covered & .29 & .13 & -.08 & $\mathbf{. 4 2}$ \\
\hline
\end{tabular}

The highest level of similarity is between Introduction to Algebra and Analytic Algebra, with all aligned components being considered equal using the Lorenzo-Seva and ten Berge (2006) guidelines and with a total Tucker congruence coefficient of 0.97. Each of the other comparisons of component solutions have high levels of similarity. Analytic Algebra and Trends in Contemporary Nursing have two similarity values marginally below the threshold to be considered equal, whereas the Introduction to Algebra and Trends in Contemporary Nursing comparison has three similarity values marginally below the threshold. Both comparisons have a total Tucker congruence coefficient of 0.93 .

Table 11

The Similarity Matrices at the Component Level for Three CTU Courses

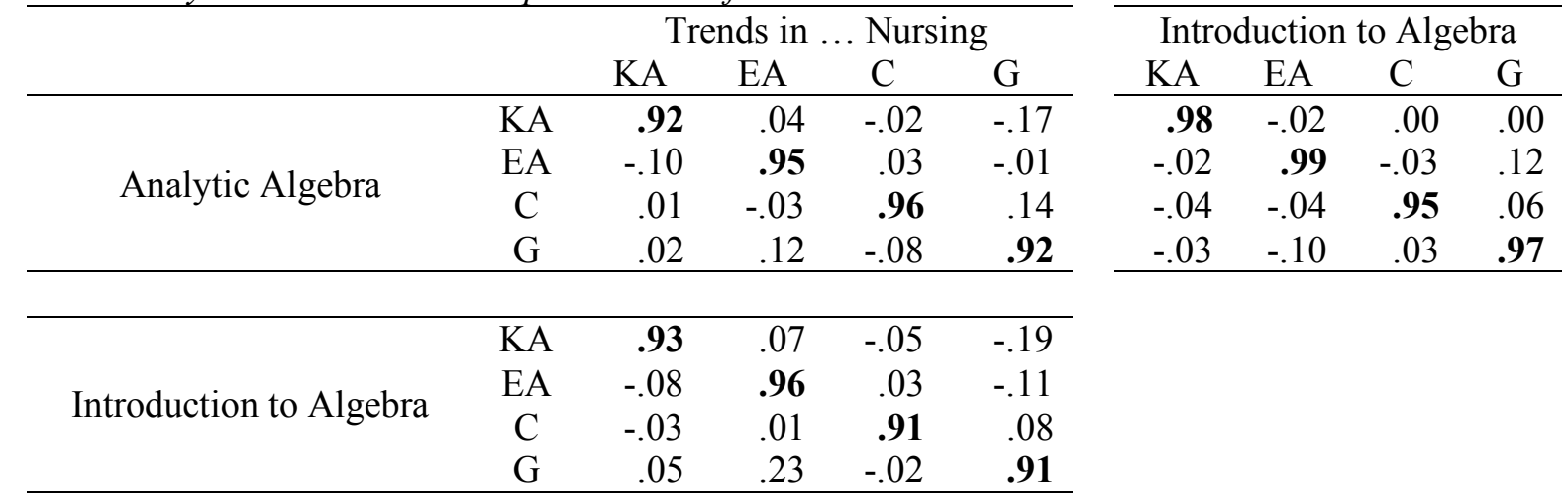

As with the UCF course solutions, all CTU course solutions can, given such high levels of similarity, be considered equal or approximately so. We have shown that the cognitive organization of adaptive learning within an institution is constant across these courses. Now, our attention turns to cross-institutional comparisons. 


\section{Cross-Institutional Comparisons-Entire Samples}

We begin the cross-institutional comparisons with the entire sample from each institution. Given the high level of internal similarity of solutions for each institution, one can expect the solution for each entire sample to capture the course-level solutions quite well. This can be verified by examination of the component-level Tucker congruence coefficients. This detail of analysis is not provided here, but the similarity matrices comparing the entire samples to individual courses are provided in Appendix A for the reader to verify, if desired.

The component pattern matrices for the entire sample from UCF and CTU are given in Table 12 and Table 13, respectively. The four extracted components in the UCF entire sample pattern solution have associated eigenvalues of $4.1,2.3,1.9$, and 1.5 , meaning they capture $75.4 \%$ of the variance in the original 13 variables. The components have an absolute average correlation of 0.21 . The CTU components have associated eigenvalues of 3.4, 2.6, 1.6, and 1.4 and capture $69.2 \%$ of the variance. These four components have an absolute average correlation of 0.10 .

Table 12

Transformed (Promax) Pattern Matrix for the Realizeit Indices, Entire Sample at $U C F(n=1,528)$

\begin{tabular}{lrrrr}
\hline & \multicolumn{4}{c}{ Components } \\
Item & KA & EA & \multicolumn{1}{c}{ C } & \multicolumn{1}{c}{ G } \\
\hline Calculated & $\mathbf{. 9 5}$ & .04 & -.01 & .12 \\
Knowledge covered & $\mathbf{. 9 5}$ & .02 & .02 & .13 \\
Knowledge state & $\mathbf{. 9 1}$ & .01 & -.10 & .02 \\
Determine knowledge & $\mathbf{. 7 9}$ & -.06 & .12 & -.21 \\
Average score & .37 & .02 & -.20 & -.15 \\
Total activities & -.05 & $\mathbf{. 9 7}$ & -.02 & -.09 \\
Num. revised & -.02 & $\mathbf{. 9 0}$ & -.15 & .00 \\
Num. practiced & .11 & $\mathbf{. 6 1}$ & .16 & -.25 \\
Interactions & -.01 & -.02 & $\mathbf{. 9 8}$ & .01 \\
Messages sent & -.01 & -.02 & $\mathbf{. 9 8}$ & .01 \\
Knowledge covered growth & .05 & -.11 & .04 & $\mathbf{. 9 3}$ \\
Knowledge state growth & -.06 & -.05 & -.09 & $\mathbf{. 9 2}$ \\
Total time & -.04 & .30 & .24 & $\mathbf{. 4 4}$ \\
\hline
\end{tabular}

Table 13

Transformed (Promax) Pattern Matrix for the Realizeit Indices, Entire Sample at $C T U(n=11,782)$

\begin{tabular}{lrrrr}
\hline \multirow{2}{*}{ Item } & \multicolumn{4}{c}{ Components } \\
& KA & EA & \multicolumn{1}{c}{ C } & \multicolumn{1}{c}{$\mathrm{G}$} \\
\hline Calculated & $\mathbf{. 9 6}$ & .09 & -.01 & -.04 \\
Average score & $\mathbf{. 9 0}$ & -.13 & -.01 & .06 \\
Knowledge state & $\mathbf{. 8 9}$ & -.18 & -.03 & .02 \\
Knowledge covered & $\mathbf{. 7 9}$ & .20 & .03 & -.06 \\
Total activities & -.04 & $\mathbf{. 9 2}$ & .02 & .03 \\
Num. revised & -.01 & $\mathbf{. 8 1}$ & -.10 & -.01 \\
Total time & -.01 & $\mathbf{. 6 9}$ & .03 & .12 \\
Num. practiced & .03 & $\mathbf{. 4 7}$ & .07 &.- .40 \\
Messages sent & .05 & -.10 & $\mathbf{. 9 2}$ & .02 \\
Interactions & -.07 & .05 & $\mathbf{. 9 0}$ & -.02 \\
Knowledge state growth & .04 & -.01 & .03 & $\mathbf{. 7 9}$ \\
Knowledge covered growth & .08 & .27 & .06 & $\mathbf{. 7 1}$ \\
Determine knowledge & .14 & .13 & .08 & $\mathbf{- . 5 6}$ \\
\hline
\end{tabular}


The measures of congruence or similarity between the individual components for the entire sample from each institution are given in Table 14. As with some previous comparisons, the alignment is along the main diagonal. Using the Lorenzo-Seva and ten Berge (2006) guidelines, the first, second, and fourth components can be considered to have a fair level of congruence, while the third components can be considered equal. All other components' congruence coefficients are close to zero and show no similarity. The total Tucker congruence coefficient between these samples is 0.91 (see Table 15).

Table 14

The Tucker Congruence Coefficient Between Individual Components for the Entire Sample From Each Institution

\begin{tabular}{lcrrrr}
\hline & & \multicolumn{4}{c}{ UCF entire sample } \\
& & KA & EA & \multicolumn{1}{c}{ C } & \multicolumn{1}{c}{ G } \\
\hline & KA & $\mathbf{. 8 9}$ & .01 & -.10 & .07 \\
CTU entire sample & EA & .05 & $\mathbf{. 9 0}$ & .06 & .17 \\
& C & .02 & -.04 & .97 & .04 \\
& G & -.24 & -.14 & -.09 & .89 \\
\hline
\end{tabular}

The source of the slightly lower levels of similarity between the KA, C, and G components can be found by examining the pattern matrices in Table 12 and Table 13. Not all variables load onto the same components or with the same weight. For example, the variable Average Score loads on the first component in the solution from the CTU sample but not in the pattern from UCF sample. Despite these differences, there is a remarkable level of agreement on the component solutions across the two very different institutions. The similarity metrics are equal or marginally below equal, allowing us to consider the solution underlying these two very different institutions to be approximately equal. This, along with our previous findings, is evidence that the cognitive organization of adaptive learning is independent of the institution, setting, or context.

The focus of the final comparison section is to take this cross institutional analysis down to the course level and confirm the findings at the institution level. To accomplish this, we pair off similar courses across the institutions. We begin by comparing the two UCF algebra courses with the two algebra courses from CTU, before moving on to the nursing courses from each institution. Cross-institutional comparisons outside of these are not described here. However, their similarity matrices are available in Appendix A.

\section{Table 15}

The Total Tucker Congruence Coefficient for Cross-Institutional Comparisons

\section{CTU}

\begin{tabular}{clcccc} 
& & $\begin{array}{c}\text { Trends in... } \\
\text { Nursing }\end{array}$ & $\begin{array}{c}\text { Analytic } \\
\text { Algebra }\end{array}$ & $\begin{array}{c}\text { Intro. to } \\
\text { Algebra }\end{array}$ & $\begin{array}{c}\text { Entire } \\
\text { Sample }\end{array}$ \\
\hline \multirow{4}{*}{ UCF } & Pathophysiology & .80 & .87 & .89 & .89 \\
& College Algebra & .82 & .91 & .93 & .93 \\
& Inter. Algebra & .82 & .91 & .93 & .92 \\
& Entire Sample & .81 & .89 & .91 & .91 \\
\hline
\end{tabular}




\section{Cross-Institutional Comparisons-Individual Course Level}

The pattern matrices for each of the algebra courses have been provided in previous sections, with the solutions behind the courses within each institution showing a high level of similarity. While there is an order to each institution's courses (CTU's Introduction to Algebra precedes Analytics Algebra, and UCF's Intermediate Algebra precedes College Algebra), there is no definitive matching of the courses across the institutions, so all four possible comparisons are made. Table 16 displays the matrices containing the component-level similarities for each of the four possible comparisons.

Beginning with UCF's Intermediate Algebra and in each of the CTU algebra courses, we again see the swapping of Components 3 and 4 . All similarity metrics are above the threshold to be considered fair, with three being above the higher threshold to be considered equal. The total Tucker congruence coefficients for UCF's Intermediate Algebra compared with CTU's Analytics Algebra and CTU's Introduction to Algebra are 0.91 and 0.93, respectively (see Table 15).

The similarity between UCF's College Algebra and each of the CTU algebra courses is generally high, above the fair threshold, with two exceptions. Both exceptions occur on the fourth component in each comparison. These similarity values are just on the border of being fair. The total Tucker congruence coefficients for UCF's College Algebra compared with CTU's Analytics Algebra and CTU's Introduction to Algebra are again 0.91 and 0.93 respectively, see Table 15. Despite the two slightly lower component-level values, the remaining high-level coefficients along with the high total similarity values again allow us to consider the pattern solutions as approximately equal.

\section{Table 16}

The Tucker Congruence Coefficient Between Individual Components for the Algebra Courses in Each Institution

\begin{tabular}{lccccccccc}
\hline & \multicolumn{1}{c}{ UCF-Intermediate Algebra } & \multicolumn{4}{c}{ UCF-College Algebra } \\
\hline & & KA & EA & G & C & KA & EA & C & G \\
& KA & $\mathbf{. 8 9}$ & .02 & .06 & -.06 & $\mathbf{. 9 5}$ & -.07 & -.04 & -.04 \\
& EA & .03 & $\mathbf{. 9 0}$ & .20 & .04 & .05 & $\mathbf{. 9 0}$ & -.04 & .26 \\
CTU-Analytic Algebra & C & -.05 & .04 & -.03 & $\mathbf{. 9 4}$ & -.05 & -.02 & $\mathbf{. 9 4}$ & -.04 \\
& G & -.23 & -.12 & $\mathbf{. 9 2}$ & -.01 & -.16 & -.30 & -.03 & $\mathbf{. 8 4}$ \\
& & & & & & & & & \\
& KA & $\mathbf{. 9 0}$ & .04 & .09 & -.10 & $\mathbf{. 9 4}$ & -.03 & -.07 & .01 \\
& EA & .06 & $\mathbf{. 9 4}$ & .09 & .04 & .06 & $\mathbf{. 9 4}$ & -.04 & .18 \\
CTU-Introduction to Algebra & C & .04 & -.01 & .05 & $\mathbf{. 9 7}$ & .02 & -.02 & $\mathbf{. 9 8}$ & .07 \\
& G & -.21 & .03 & $\mathbf{. 9 2}$ & -.04 & -.15 & -.16 & -.04 & $\mathbf{. 8 3}$ \\
\hline
\end{tabular}

The final comparison examines the nursing courses in each institution. The componentlevel similarity values are given in Table 17. Here we see something different occurring than in the other comparisons. Only two components have high enough similarity to be considered fair using the guidelines. The other two have similarity coefficients that fall below the threshold, with the similarity of the first components in each solution falling far below the threshold. The total 
Tucker congruence coefficient for the comparison of these two pattern solutions is 0.80 (see Table 15), again below the threshold to be considered fair.

Table 17

The Tucker Congruence Coefficient Between Individual Components for the Nursing Courses in Each Institution

\begin{tabular}{cccccc}
\hline & & \multicolumn{4}{c}{ UCF-Pathophysiology } \\
& & KA & EA & \multicolumn{1}{c}{ G } & \multicolumn{1}{c}{ C } \\
\hline & KA & $\mathbf{. 6 6}$ & .16 & .02 & -.22 \\
CTU-Trends in ... Nursing & EA & .14 & $\mathbf{. 9 0}$ & .21 & .07 \\
& C & -.07 & .12 & -.14 & $\mathbf{. 8 9}$ \\
& G & -.43 & .12 &. $\mathbf{7 9}$ & .06 \\
\hline
\end{tabular}

In fact, we can observe that the total Tucker congruence coefficients are low for all comparisons involving the CTU nursing course and any of the UCF courses. There is something different about the solution of CTU's Trends in Contemporary Nursing course, which means we cannot treat its solution as equal, as we have done with all other patterns comparisons. This is likely because this course is not delivered fully through the adaptive platform. Two of the five weeks, including assessment, are delivered through traditional means. The fact that the KA and G components have low similarity values make sense considering this. While there is a difference in the solutions, there is still a high level of agreement between this course and the other courses, and the interpretation of this nursing course will not differ dramatically from that of the other courses.

\section{Interpretation of Components}

The preceding pattern matrices and similarity coefficients provide an indication that the underlying dimensions of adaptive learning remain stable within disciplines, across disciplines, and across the two universities. Although there is not complete correspondence across courses at UCF and CTU, the component similarity and invariance found in this study can be considered stable. The algebra courses align quite well; however, the nursing comparison is, at best, an approximation because comparing Pathophysiology with Trends in Contemporary Nursing reflects only a mild curricular relationship. There will always be some random variation in the results causing some variables to be unstable, drift in and out of components, and at times change their sign. This, along with our previous caveat on using the similarity interpretation guidelines as absolute standards, indicates that the findings have remained constant enough for us to make the following assertion: Based on the Realizeit indices, there are four components that comprise the adaptive learning educational environment.

Knowledge Acquisition (KA): This is the dominant component in every solution and showed consistent correspondence across all patterns. Although each variable did not appear in every KA component, it involved the following measures: calculated, knowledge state, knowledge covered, determine knowledge, and average score. These measures relate to educational achievement and have a mastery element associated with them. Knowledge acquisition in adaptive learning assesses learning prior to, during, and upon completion of a course and forms the benchmark for student success. In addition, it serves as the basis of the decision engine's recommendation about the appropriate learning path for students and an early indication of possible difficulties in the learning sequence. This component forms the basis of effective course 
design and pedagogy. Knowledge acquisition appears first, is the strongest, and is the learning engine that makes cognitive growth possible.

Engagement Activities (EA): This component, appearing in every solution, bears a strong relationship to what Carroll called the time students spent in actual learning and relates to how much energy a student expends in the learning process. If one could hold ability level constant, a reasonable assumption might be that students who are more engaged in learning activities (albeit effective ones, not just marking time) will score higher on knowledge acquisition. This component is formed by relationships among total activities, number revised, total time, and number practiced, again, with not every variable appearing in every pattern. This dimension asks the following questions: How much did you do, how much did you revise, how much did you practice, and how much time did you spend in the course? There is an adage that $100 \%$ of people who do not buy lottery tickets do not win. That analogy seems to hold for adaptive learning. As a student, you may succeed with minimal engagement, but the chances of success are much greater in the adaptive modality if you do many activities, practice, and do some thoughtful revision.

Growth $(G)$ : At this point, the components become slightly more unstable. Growth is a clear expectation for any course. Measuring change in knowledge acquisition can result from many baseline measures and is a vital element of the learning cycle. In most cases, this component is formed by knowledge state growth and knowledge covered growth, with appearances in various places by number practiced, determine knowledge covered, and total time. Clearly, however, growth is change in what information a student has mastered and is the key bellwether for student progress in their adaptive learning courses. So far then, we have established the importance of the following: How much knowledge did you acquire, how much did you really engage, and how much did you grow? Although more variable, this dimension appeared in every pattern we derived.

Communication $(C)$ : Finally, communication emerges in the Realizeit platform, enabled by messages sent and interactions. Within the constraints of this modality, this is the social learning dimension of adaptive learning and the way students communicate with each other and their instructors - it indexes the interaction patterns found in adaptive learning. This dimension underlies the effort students expend communicating with each other, their instructors, and how their instructors communicate with them. Although this component is relatively independent of EA on a correlation index, it bears a strong conceptual relationship.

\section{Additional Remarks About Complexity}

Before concluding, it is worth pointing out several other interesting findings. These are highlighted by Table 18, which displays a count of the number of times each variable loaded on a component. 
Table 18

Number of Times Each Variable Loaded on Each Component

\begin{tabular}{lcccc}
\hline & \multicolumn{4}{c}{ Component } \\
Variable & KA & EA & C & G \\
\hline Calculated & $\mathbf{8}$ & & & \\
Knowledge state & $\mathbf{8}$ & & & \\
Average score & $\mathbf{6}$ & & 1 & 1 \\
Knowledge covered & 7 & & & 4 \\
Determine knowledge & 4 & & & 4 \\
Number practiced & & 7 & & 1 \\
Total time & & 7 & & \\
Number revised & & $\mathbf{8}$ & $\mathbf{8}$ & \\
Total activities & & $\mathbf{8}$ & $\mathbf{8}$ & \\
Interactions & & & & $\mathbf{8}$ \\
Messages sent & & & & \\
Knowledge state growth & & 1 & & \\
Knowledge covered & & & & \\
Growth & & & & \\
\hline
\end{tabular}

First, we see the general pattern in each of the components emerging. This makes sense and reaffirms the high level of similarity across the various solutions. Second, notice that the determine knowledge variable loads as often on the Knowledge component as on the growth components. Examining the pattern matrices, we can see that this split is by institution. In UCF the determine knowledge variable always loads on the knowledge component, and in CTU it always loads on growth. Determine knowledge acts as a pretest on each milestone within a course and measures a student's level of prior knowledge of the concepts within that milestone. The variable measures the percentage of milestones on which the student used the determine knowledge functionality. This difference could be due to the fact that the determine knowledge functionality is being used differently in each institution. In CTU it is almost mandatory, and its use is highly encouraged by the instructors. In UCF it is an optional feature that the student can choose to use if they wish.

We see a similar loading on multiple components with the number practiced variable, which measures the number of times a student practices answering questions on concepts they have already completed. However, in this case, we do not see an even split, with the variable sometimes loading on both the effort and growth and sometimes loading on one of these components. Here the split is not by institution, as with determine knowledge, nor is it by subject domain. Again, this may suggest that this functionality is being used differently in some of these courses. It is interesting that this does not happen for the variable that counts the number of revisions. In the system, a revision includes both learning content and questions and is a targeted action on a single concept. The motivation for using the revision functionality, generally remediation, is likely different from the motivation for using practice, improvement of grade, and reinforcement of knowledge. 


\section{Limitations}

There are limitations inherent in this research because the scope and generalizability are constrained. First, the study involves only two universities (UCF and CTU), one adaptive learning platform (Realizeit), and two subject areas (algebra and nursing). Although the investigators have high confidence in the validity of their findings, at best this should be considered a pilot study that may or may not generalize to all universities, disciplines, or adaptive learning platforms. Replication and expansion will add legitimacy to these findings.

Secondly, the dependent measures used to develop the component patterns are internally generated metrics provided by Realizeit. Although they prove very useful for documenting and understanding student outcomes, modeling learning behaviors, and accurately predicting which students are likely to be successful, the external validity of this research line can be strengthened. Specifically, this can be accomplished by adding achievement, behavior, and engagement variables generated outside Realizeit. This would allow for an integrated domain study where what has been accomplished in this paper might be augmented by interbattery component analysis that would anchor the Realizeit data to external validation metrics.

Thirdly, the course comparisons are formulated at the most general level. Introductory and Intermediate Algebra have not been corroborated by topic, nor have the algebra courses. In the nursing domain, Pathophysiology is highly technical and skills based, while Trends in Contemporary Nursing has more general outcome expectations.

Finally, the practical implications of the results for this study have yet to be demonstrated. Principal components are latent, nonobservable variables. We argue here that because those dimensions have remained constant and stable over such a variety of contexts, they are important. However, this study has taken place in the realm of abstraction. As a result, causal inferences, if they exist, are not identified in this study. A logical next step would be to compute and analyze the component scores for each solution within and across courses and universities.

\section{Discussion}

\section{The Positives}

Time. Adaptive learning creates a fluid educational environment responding to the needs of many student cohorts. Features like initial student knowledge baselines, continuous assessment and feedback, redesigned learning paths, mastery certification, and instructional format preference make a more flexible and responsive educational landscape. In the introduction we mention adaptive learning's modification of learning time. Adam (2004), in her work with temporal culture, provides insights into what can happen with constant outcomes and variable learning time.

Learning transforms the following aspects of a student's experience:

1. Time frame: The time boundaries of a course or program of study

2. Timing: When learning occurs

3. Tempo: The pace of learning

4. Duration: How long learning activities last

5. Sequence: The order in which learning will take place 
Norberg, Dziuban, and Moskal (2011) incorporate these elements in their time-based model of blended (or adaptive) learning, grouping the educational process into synchronous and asynchronous modalities

Poverty. Adaptive learning addresses a problem in our society that, unfortunately, originates with our educational system. The expected college graduation rate for American youths living in the lowest economic quartile is approximately $9 \%$, while that projection for the top quartile is $77 \%$ (Cahalan \& Perna, 2015). If you grow up in poverty in this country, the odds against your getting a degree are nine to one. Economists place the increase in lifetime earnings from a bachelor's degree at approximately one million dollars - enough to raise someone from poverty into the middle class (Carnevale, Rose, \& Cheah, 2013). Staggering college debt complicates the problem. Estimates place the current average indebtedness for college graduates at $\$ 37,000$ - an amount that disproportionately impacts students living in poverty (Fay, 2018; Lochner \& Monge-Naranjo, 2015). The problem is complex, but the answer is clear. Increase educational success and communities will transform themselves. However, this demands excellent education early, high expectations, continual support, and assurance that when students have an opportunity to attend vocational school, community college, or a university, the money will be available (Weiss, 2017). The cost is considerable, but the return on investment to our society will be immense (Lochner, 2010). We cannot afford not to educate our young people.

Why do students from poor neighborhoods struggle with education? Mullainathan and Shafir (2013) argue that they live in scarcity - having many more needs than resources to meet them. Students have to work at jobs with irregular hours that make time management difficult. Health care and family responsibilities place additional pressures on them. They borrow money to attend college because the complexities of applying for scholarships are overwhelming.

What does this have to do with higher education and adaptive learning? Consider what happens when an overwhelmed student misses class. The next one becomes difficult or impossible because it depends on understanding content from the previous session. Miss another one, and perhaps dropping out becomes the only option. Each class building on the previous one is not an optimal situation for students who are overloaded by scarcity.

In contrast, consider an adaptive learning course with modules supported by learning nodes and a go-at-your-own-pace design. The system can place a student at the optimal starting point corresponding to her estimated competency level. At its full potential, when running properly and with faculty support, adaptive learning can help address the scarcity problem. By empowering students to manage their learning using adaptive learning systems that identify the goal, locate where they should start, and present them with options about how they can get there, we empower instead of impede them.

A new learning taxonomy. The positives of adaptive learning coalesce around a facilitated yet rigorous educational environment. Scheduling becomes easier, giving students more control over their life circumstances. Class size is not an issue because education becomes a one-to-one experience, and the inherent design of adaptive learning requires clearly specified course requirements. Progress assessment becomes more authentic and continuous. Therefore, students see an increased likelihood of obtaining a degree and become more engaged and committed to persisting. They become active participants in their own evaluation because response time is faster. Discussing information communication technologies, Floridi $(2013$, 2014) coincidentally developed a learning taxonomy for adaptive learning: 
Information: Things a student knows

Insipience: Knowledge a student lacks

Uncertainty: Things a student is not quite sure he or she knows

Ignorance: Things a student does not know he or she does not know

This taxonomy is the design specification for adaptive learning because, metaphorically, students and instructors have much more skin in the game, so there is symmetry in the responsibility for learning (Taleb, 2018).

\section{The Issues}

All new instructional technologies have issues, and adaptive learning's challenges include some associated with the platforms and others with education in our society. Unfortunately, we overestimate short-term results and underestimate long-term outcomes. The mixed results reported in the background section of this article can lead us to fall into that trap. The impact of adaptive learning will be realized over the long haul-years or possibly decades. Without this mindset we will jettison this pedagogy like we have done with so many others. Do adaptive learning platforms work flawlessly? No, they do not and probably never will, but they are getting much better. Just like students, they need time.

Ambivalence. Unfortunately, there is a growing ambivalence in our society about the value of an education - both intellectually and financially. Students are increasingly disenchanted with their life benefits after obtaining a degree. Consider this quote from the Wizard of $\mathrm{Oz}$ :

Back where I come from, we have universities, seats of great learning, where men go to become great thinkers. And when they come out, they think deep thoughts and with no more brains than you have. But they have one thing you haven't got: a diploma. (Baum, as cited in Caplan, 2018, p. 1)

Idealized cognitive models and boundary objects. Contemporary education and adaptive learning have two confounding issues. The first is an idealized cognitive model (ICM) (Lakoff, 2008). An ICM is a frame arbitrarily constructed because we need to make sense of our world. A good example relates to time: for instance, the notion of a month. There is no month in nature. We invented it because we needed some way of dealing with the passage of time. A month exists in the context of a year-another ICM. These are completely arbitrary, and it doesn't take much research to discover that cultures all over the world mark the passage of time differently. Adaptive learning is an ICM and is the reason we experience such difficulty forming precise definition. As an ICM it is useful but not precise as a treatment effect.

The adaptive ICM issue is confounded by Bowker and Star's (2000) theory of a boundary object. Adaptive learning is a good example. A boundary object is robust enough to hold a community of practice together but relatively weak in that community. However, individual constituencies have a very strong definition. For instance, each platform provider has a clear specification of adaptive learning that guides their system development, but they don't necessarily agree with each other. The same is true across universities. Critical thinking is another example of a boundary object. Most university communities are in favor of it, but specific disciplines disagree on its definition and composition. Adaptive learning is both an ICM and boundary object, making definition and evaluation a challenge. Both are important and necessary but increase complexity. The research objective is to move from data to information to insight to action. However, because adaptive learning is an idealized cognitive model and boundary object, we must function under the influence of uncertain mediation (Setenyi, 1995) where data are imprecise, ambiguous and at times contradictory. 


\section{Conclusion}

Adaptive learning remains stable across diverse disciplines in two universities with different organizational structures and student populations. UCF is one of the largest public universities in the country, and CTU is one of the most successful for-profit institutions in higher education. Both campuses use adaptive learning to serve the needs of their student cohorts - UCF accommodates scale and diversity while CTU responds to working adults who comprise a large percentage of its student population.

The analysis is objective because the principal components analysis does not integrate the variable labels we describe; therefore, it discounts confirmation bias. The method reproduces the largest proportion of the correlation matrix with the smallest number of dimensions, thereby reducing a complex system of pairwise relationships into a simplified explanatory model. The components are clear and unambiguous involving achievement, growth engagement, and communication. Learning science suggests that there is a clear relationship between these traitsengagement and communication are prerequisites for growth and achievement. However, in this study they are statistically independent of each other. The irony is that the four constructs are no surprise, because educators know that this underlying pattern is fundamental to effective teaching and learning in all modalities, not just adaptive ones.

Because of its responsiveness, adaptive learning enables universities to accommodate demographically diverse student cohorts, potentially leveling the educational playing field. This modality acknowledges the increasingly important student voice. Learners want reduced uncertainty about how to proceed in a course without disruption from work and family demands. They want an improved sense of control and a method to monitor progress with responsive and authentic assessment. Understanding the rules and having clear course expectations at the outset are prerequisite for their engagement. Students expect a more responsive education giving them more learning latitude that increases their agency and executive control. All course modalities can accommodate the four components, but adaptive learning seems particularly well suited to them, and as the platforms improve, we conclude that students will become a more active part of teaching and learning. Presence is taking on whole new meaning.

This study is a collaboration between two universities and their common adaptive learning platform provider. Each organization brings different strengths to the partnership. CTU achieves scale with adaptive implementation. UCF integrates research and data into the decision-making and policy process. Realizeit brings advanced analysis skills and makes transparent analytic data available to all its partners. Because of this small network, each organization improves its adaptive learning process - the universities with pedagogy and Realizeit with its platform. This happens in a nonlinear process that encounters a good deal of productive failure. The technology does not drive the work, but rather the research helps improve the technology. The partners commit to pushing information and flexibility out as far as possible and believe that progress happens in small steps. Simple is more effective. Without the partnership and the sharing, there would be no study. None of us could do this alone. Therefore, our major conclusion is that we need more extensive collaborative work. Each university can contextualize adaptive learning, and every platform provider can support an active research agenda to form an increasingly productive, collaborative partnerships. 


\section{References}

Adam, B. (2004). Time. Cambridge, UK: Polity.

Alli, N., Rajan, R., \& Ratliff, G. (2016). How personalized learning unlocks student success. EDUCAUSE Review Online, 51(2). Retrieved from https://er.educause.edu/articles/2016/3/how-personalized-learning-unlocks-studentsuccess

Argyris, C. (1960). Understanding organizational behavior. Oxford, England: Dorsey.

Association of Public \& Land-Grant Universities. (2016). Personalizing learning with adaptive courseware. Retrieved from http://www.aplu.org/projects-and-initiatives/personalizedlearning-consortium/plc-projects/plc-adaptive-courseware/

Bailey, A., Vaduganathan, N., Henry, T., Laverdiere, R., \& Pugliese, L. (2018, March). Making digital learning work: Success strategies from six leading universities and community colleges. The Boston Consulting Group.

Bastedo, K., \& Cavanagh, T. (2016, April 19). Personalized learning as a team sport: What IT professionals need to know. EDUCAUSE Review. Retrieved from https://er.educause.edu/articles/2016/4/personalized-learning-as-a-team-sport-what-itprofessionals-need-to-know

Becker, S. A., Cummins, M., Davis, A., Freeman, A., Hall, C. G., \& Ananthanarayanan, V. (2017). NMC horizon report: 2017 higher education edition (pp. 1-60). The New Media Consortium.

Betts, K., \& Heaston, A. (2014). Build it but will they teach? Strategies for increasing faculty participation \& retention in online \& blended education. Online Journal of Distance Learning Administration, 17(2), n2.

Bienkowski, M., Feng, M., \& Means, B. (2012). Enhancing teaching and learning through educational data mining and learning analytics: An issue brief. US Department of Education, Office of Educational Technology, 1, 1-57.

Bill \& Melinda Gates Foundation. (2014, November). Early progress: Interim research on personalized learning. Retrieved from http://collegeready.gatesfoundation.org/wpcontent/uploads/2015/06/Early-Progress-on-Personalized-Learning-Full-Report.pdf

Bowker, G. C., \& Star, S. L. (2000). Sorting things out: Classification and its consequences. Cambridge, MA: The MIT press.

Brown, J. (2015). Personalizing post-secondary education: An overview of adaptive learning solutions for higher education. Retrieved from http://www.sr.ithaka.org/wpcontent/uploads/2015/08/SR_Report_Personalizing_Post_Secondary_Education_31815 $\underline{0 . p d f}$

Buchanan, T., Sainter, P., \& Saunders, G. (2013). Factors affecting faculty use of learning technologies: Implications for models of technology adoption. Journal of Computing in Higher Education, 25(1), 1-11. 
Cahalan, M., \& Perna, L. (2015). Indicators of higher education equity in the United States: 45 year trend report. Pell Institute for the Study of Opportunity in Higher Education. Retrieved from https://files.eric.ed.gov/fulltext/ED555865.pdf

Carnevale, A. P., Rose, S. J., \& Cheah, B. (2011). The college payoff: Education, occupations, lifetime earnings. Washington, DC: Georgetown University Center on Education and the Workforce.

Caplan, B. (2018). The case against education: Why the education system is a waste of time and money. Princeton: Princeton University Press.

Carroll, J. B. (1963). A model of school learning. Teachers College Record, 64(8), 723-723.

Center for Distributed Learning Division of Digital Learning. (n.d.). We are the Center for Distributed Learning. Retrieved from https://cdl.ucf.edu/

Chan, W., Ho, R. M., Leung, K., Chan, D. K., \& Yung, Y. (1999). An alternative method for evaluating congruence coefficients with Procrustes rotation: A bootstrap procedure. Psychological Methods, 4(4), 378-402. doi:10.1037/1082-989X.4.4.378

Chen, B., Bastedo, K., Kirkley, D., Stull, C., \& Tojo, J. (2017). Designing personalized adaptive learning courses at the University of Central Florida. ELI Brief. Retrieved from https://library.educause.edu/resources/2017/8/designing-personalized-adaptive-learningcourses-at-the-university-of-central-florida

Daines, J., Troka, T., \& Santiago, J. (2016). Improving performance in trigonometry and precalculus by incorporating adaptive learning technology into blended models on campus. In 123rd Annual ASEE Conference \& Exposition, New Orleans, Louisiana.

Diamond, J. (2005). Guns, germs, and steel: The fates of human societies. New York: Norton. du Boulay, B. (2006). Commentary on Kurt VanLehn's "The Behaviour of Tutoring Systems." International Journal of Artificial Intelligence in Education, 16(3), 267-270.

Dziuban, C. (2017). The technology of adaptive learning. Education Technology Insights. Retrieved from https://digital-solution.educationtechnologyinsights.com/cxoinsights/thetechnology-of-adaptive-learning-nid-280.html

Dziuban, C. D., Moskal, P. D., Cassisi, J., \& Fawcett, A. (2016). Adaptive learning in psychology: Wayfinding in the digital age. Online Learning, 20(3), 74-96.

Dziuban, C., Howlin, C., Johnson, C., \& Moskal, P. (2017, December 18). An adaptive learning partnership. EDUCAUSE Review. Retrieved from https://er.educause.edu/articles/2017/12/an-adaptive-learning-partnership

Dziuban, C., Moskal, P., \& Hartman, J. (2016, September 30). Adapting to learn, learning to adapt. EDUCAUSE Center for Analysis and Research (ECAR) Research Bulletin. Louisville, CO: ECAR. Retrieved from https://library.educause.edu/resources/2016/9/adapting-to-learn-learning-to-adapt

Dziuban, C., Moskal, P., Johnson, C., \& Evans, D. (2017). Adaptive learning: A tale of two contexts. Current Issues in Emerging eLearning, 4(1), 3. 
Dziuban, C., Moskal, P., Kramer, L., \& Thompson, J. (2013). Student satisfaction with online learning in the presence of ambivalence: Looking for the will-o'-the-wisp. The Internet and Higher Education, 17, 1-8.

Fay, B. (2018, May). Students \& debt. Retrieved from https://www.debt.org/students/

Floridi, L. (2013). Spreading ignorance equally. The Philosophers'Magazine, (63), 24-25.

Floridi, L. (2014). The 4th Revolution. Oxford: Oxford University Press.

Gardner, H. (2011). Frames of mind: The theory of multiple intelligences. New York: Basic Books.

Gelsinger, P. (2018, March/April). Mind-blowing to mundane: How tech is reshaping our expectations. MIT Technology Review, 121(2), 7.

Goldberg, L. R. (1992). Goldberg's 100 unipolar Big-Five factor markers. Psychological Assessment, 4(1), 26-42.

Hendrickson, A. E., \& White, P. O. (1964). Promax: A quick method for rotation to oblique simple structure. British Journal of Statistical Psychology, 17(1), 6-70. Retrieved from http://onlinelibrary.wiley.com/doi/10.1111/j.2044-8317.1964.tb00244.x/pdf

Howlin, C. P., \& Lynch, D. (2014). A framework for the delivery of personalized adaptive content. 2014 International Conference on Web and Open Access to Learning (ICWOAL), (pp. 1-5). doi:10.1109/ICWOAL.2014.7009203

Johnson, C., \& Zone, E. (In review). Achieving a scale implementation of adaptive learning through faculty engagement: A case study. Current Issues in Emerging eLearning.

Johnson, D. (2017, June 15). Opening the black box of adaptivity. EDUCAUSE Review. Retrieved from https://er.educause.edu/blogs/2017/6/opening-the-black-box-of-adaptivity

Kaiser, H. F., \& Rice, J. (1974). Little Jiffy, Mark IV. Educational and Psychological Measurement, 34, 111-117.

Kennedy, A. (2015). Faculty perceptions of the usefulness of and participation in professional development for online teaching: An analysis of faculty development and online teaching satisfaction. Nursing Research and Practice, Volume 2017, Article ID 9374189. https://doi.org/10.1155/2017/9374189.

Kibble, T. (2015). The standard model of particle physics. European Review, 23(1), 36-44. doi:10.1017/S1062798714000520

Lakoff, G. (2008). Women, fire, and dangerous things. Chicago: University of Chicago Press.

Legon, R., \& Garrett, R. (2018). The changing landscape of online education (CHLOE) 2: A deeper dive. CHLOE2. Retrieved from https://www.qualitymatters.org/qaresources/resource-center/articles-resources/CHLOE-2-report-2018

Lochner, L. (December 2010). Measuring the impacts of the Tangelo Park project on local residents. University of Western Ontario.

Lochner, L., \& Monge-Naranjo, A. (2015). Student loans and repayment: Theory, evidence and policy (No. w20849). National Bureau of Economic Research. 
Lorenzo-Seva, U., \& ten Berge, J. F. (2006). Tucker's congruence coefficient as a meaningful index of factor similarity. Methodology: European Journal of Research Methods for the Behavioral and Social Sciences, 2(2), 57-64. doi:10.1027/1614-2241.2.2.57

Moskal, P., Carter, D., \& Johnson, D. (2017). 7 things you should know about adaptive learning. ELI. Retrieved from https://library.educause.edu/resources/2017/1/7-things-you-shouldknow-about-adaptive-learning

Mulaik, S.A. (2009). The foundations of factor analysis (2nd ed.). London, United Kingdom: Chapman and Hall.

Mullainathan, S., \& Shafir, E. (2013). Scarcity: Why having too little means so much. New York: Macmillan.

Nakic, J., Granic, A., \& Glavinic, V. (2015). Anatomy of student models in adaptive learning systems: A systematic literature review of individual differences from 2001 to 2013. Journal of Educational Computing Research, 51(4), 459-489. doi:10.2190/EC.51.4.e

Norberg, A., Dziuban, C., \& Moskal, P. (2011). A time-based blended learning model. On the Horizon, 19(3), 207-216.

Office of Educational Technology. (2017, January). Reimagining the role of technology in education: 2017 National Education Technology Plan update. US Department of Education. Retrieved from https://tech.ed.gov/files/2017/01/NETP17.pdf

Online Learning Consortium. (2016). Digital learning innovation award. Retrieved from https://onlinelearningconsortium.org/about/olc-awards/dlia/

Page, S. E. (2010). Diversity and complexity. Princeton, NJ: Princeton University Press.

Pugliese, L. (2016, October 17). Adaptive learning systems: Surviving the storm. EDUCAUSE Review. Retrieved from https://er.educause.edu/articles/2016/10/adaptive-learningsystems-surviving-the-storm

Quality Matters. (2014). Quality Matters ${ }^{T M}$ overview [PowerPoint slides]. Retrieved from https://www.qualitymatters.org/sites/default/files/pd-docs-PDFs/QM-OverviewPresentation-2014.pdf

Rousseau, D. M. (1990). Normative beliefs in fund-raising organizations: Linking culture to organizational performance and individual responses. Group \& Organization Studies, $15(4), 448-460$.

Setenyi, J. (1995, May). Teaching democracy in an unpopular democracy. Paper presented at What to Teach About Hungarian Democracy Conference. 12 May 1995, Kossuth Klub, Hungary.

Schönemann, P. (1966). A generalized solution of the orthogonal procrustes problem. Psychometrika, 31(1), 1. doi:10.1007/BF02289451

Smith, D. (2013). An artificial intelligence-based distance learning system. Distance Learning, $10(3), 51-56$.

Taleb, N. N. (2018). Skin in the game: Hidden asymmetries in daily life. New York: Random House. 
Thurstone, L. L. (1938). Primary mental abilities. University of Chicago Press: Chicago.

Tupes, E. C., \& Christal, R. E. (1992). Recurrent personality factors based on trait ratings. Journal of Personality, 60(2), 225-251. doi:10.1111/j.1467-6494.1992.tb00973.x

Tyton Partners. (2016). Learning to adapt 2.0: The evolution of adaptive learning in higher education. Retrieved from http://tytonpartners.com/tyton-wp/wpcontent/uploads/2016/04/Tyton-Partners-Learning-to-Adapt-2.0-FINAL.pdf

University of Central Florida. (n.d.-a). Teach online. Retrieved from https://cdl.ucf.edu/teach/

University of Central Florida. (n.d.-b). UCF facts 2017-2018. Retrieved from https:/www.ucf.edu/about-ucf/facts/

University of Central Florida. (2012). About CDL. Retrieved from https://cdl.ucf.edu/about/cdl/distributed-learning-guidelines/

Vandewaetere, M., \& Clarebout, G. (2014). Advanced technologies for personalized learning, instruction, and performance. In J. M. Spector, M. D. Merrill, J. Elen, \& M. J. Bishop (Eds.) Handbook of research on educational communications and technology (pp. 425437).

VanLehn, K. (2006). The behavior of tutoring systems. International Journal of Artificial Intelligence in Education, 16(3), 227-265.

Weiss, E. (2013, July 13). Tangelo Park program (Orlando, Florida). Broader, Bolder Approach to Education.

Wingo, N. P., Ivankova, N. V., \& Moss, J. A. (2017). Faculty perceptions about teaching online: Exploring the literature using the technology acceptance model as an organizing framework. Online Learning, 21(1), 15-35.

Yarnall, L., Means, B., \& Wetzel, T. (2016). Lessons learned from early implementations of adaptive courseware. SRI Education. Retrieved from https://www.sri.com/sites/default/files/brochures/almap_final_report.pdf 


\begin{tabular}{|c|c|c|c|c|c|c|c|c|c|c|c|c|c|}
\hline & & \multicolumn{4}{|c|}{$\begin{array}{c}\text { CTU - Trends in Contemporary } \\
\text { Nursing }\end{array}$} & \multicolumn{4}{|c|}{$\begin{array}{c}\text { CTU - Introduction to } \\
\text { Algebra }\end{array}$} & \multicolumn{4}{|c|}{$\begin{array}{c}\text { CTU - Analytic } \\
\text { Algebra }\end{array}$} \\
\hline & & KA & EA $^{\text {Nursi }}$ & $\mathrm{C}$ & G & KA & $\begin{array}{l}\text { Alge } \\
\text { EA }\end{array}$ & $\mathrm{C}$ & G & KA & $\begin{array}{l}\mathrm{Alg} \\
\text { EA }\end{array}$ & bra & $\mathbf{G}$ \\
\hline \multirow{4}{*}{$\begin{array}{l}\text { CTU - } \\
\text { Entire } \\
\text { Sample }\end{array}$} & KA & .93 & .07 & -.03 & -.18 & 1.00 & -.01 & -.01 & .01 & .99 & -.01 & -.02 & -.02 \\
\hline & EA & -.09 & .96 & .03 & -.07 & -.02 & 1.00 & -.02 & .05 & -.03 & .99 & -.03 & -.06 \\
\hline & $\mathbf{C}$ & -.01 & .02 & .93 & .09 & -.02 & -.02 & 1.00 & .02 & .00 & -.01 & .96 & .03 \\
\hline & G & .04 & .17 & -.07 & .92 & -.01 & -.04 & .00 & .99 & -.01 & .07 & .03 & .99 \\
\hline \multirow{6}{*}{$\begin{array}{l}\text { UCF - } \\
\text { Entire } \\
\text { Sample }\end{array}$} & KA & .73 & .11 & -.08 & -.44 & .89 & .06 & .04 & -.22 & .87 & .04 & -.07 & -.23 \\
\hline & EA & .03 & .86 & .10 & -.16 & .02 & .91 & -.06 & -.07 & -.01 & .88 & -.01 & -.24 \\
\hline & $\mathbf{C}$ & -.13 & .06 & .92 & .02 & -.11 & .05 & .97 & -.06 & -.09 & .04 & .93 & -.05 \\
\hline & G & .01 & .34 & -.09 & .74 & .07 & .13 & .06 & .89 & .05 & .22 & -.01 & .90 \\
\hline & & \multicolumn{4}{|c|}{ UCF - Pathophysiology } & \multicolumn{4}{|c|}{ UCF - Intermediate Algebra } & \multicolumn{4}{|c|}{ UCF - College Algebra } \\
\hline & & KA & EA & G & $\mathbf{C}$ & KA & EA & G & C & KA & EA & $\mathbf{C}$ & $\mathbf{G}$ \\
\hline \multirow{4}{*}{$\begin{array}{l}\text { CTU - } \\
\text { Entire } \\
\text { Sample }\end{array}$} & KA & .83 & .10 & .05 & -.19 & .90 & .04 & .08 & -.08 & .95 & -.04 & -.05 & -.01 \\
\hline & EA & .07 & .89 & .03 & .05 & .04 & .92 & .13 & .05 & .05 & .93 & -.03 & .21 \\
\hline & C & .03 & .02 & .01 & .96 & .02 & .02 & .02 & .98 & .01 & .00 & .98 & .04 \\
\hline & G & -.22 & .13 & .93 & -.03 & -.23 & -.04 & .92 & -.05 & -.15 & -.23 & -.06 & .83 \\
\hline \multirow{4}{*}{$\begin{array}{l}\text { UCF - } \\
\text { Entire } \\
\text { Sample }\end{array}$} & $\mathbf{K A}$ & .99 & -.02 & -.03 & -.07 & 1.00 & -.01 & .00 & -.01 & .97 & .04 & .02 & .00 \\
\hline & EA & .01 & .91 & -.19 & -.02 & .02 & .95 & -.11 & -.01 & .02 & .97 & -.04 & -.06 \\
\hline & $\mathbf{C}$ & .01 & .02 & -.05 & .98 & -.03 & .06 & -.04 & .97 & -.06 & .05 & .94 & .03 \\
\hline & $\mathbf{G}$ & .05 & .14 & .94 & .08 & -.02 & .04 & .97 & .01 & .01 & -.10 & -.02 & .97 \\
\hline
\end{tabular}

\begin{tabular}{|c|c|c|c|c|c|c|c|c|c|c|}
\hline \multirow{8}{*}{ 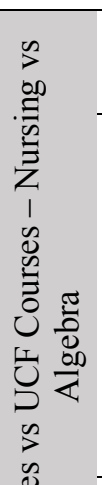 } & & & \multicolumn{4}{|c|}{ CTU - Analytic Algebra } & \multicolumn{4}{|c|}{ CTU - Introduction to Algebra } \\
\hline & & & $\mathbf{K A}$ & EA & $\mathbf{C}$ & $\mathbf{G}$ & $\mathbf{K A}$ & EA & $\mathbf{C}$ & $\mathbf{G}$ \\
\hline & \multirow{6}{*}{ UCF - Pathophysiology } & KA & .81 & .06 & -.05 & -.22 & .83 & .08 & .06 & -.20 \\
\hline & & EA & .08 & .87 & .04 & .06 & .10 & .89 & -.02 & .18 \\
\hline & & $\mathbf{G}$ & .04 & .10 & -.01 & .94 & .05 & -.01 & .03 & .92 \\
\hline & & $\mathbf{C}$ & -.18 & .05 & .91 & -.01 & -.20 & .04 & .96 & .00 \\
\hline & & & \multicolumn{4}{|c|}{ UCF - Intermediate Algebra } & \multicolumn{4}{|c|}{ UCF - College Algebra } \\
\hline & & & $\mathbf{K A}$ & EA & $\mathbf{G}$ & $\mathbf{C}$ & $\mathbf{K A}$ & EA & $\mathbf{C}$ & $\mathbf{G}$ \\
\hline$\underset{\infty}{\infty}$ & \multirow{4}{*}{$\begin{array}{c}\text { CTU - Trends in } \\
\text { Contemporary Nursing }\end{array}$} & KA & .76 & .05 & .03 & -.10 & .82 & -.07 & -.05 & -.07 \\
\hline ¿ర్ & & EA & .10 & .90 & .32 & .05 & .10 & .88 & -.01 & .40 \\
\hline$?$ & & C & -.07 & .16 & -.13 & .89 & -.08 & .10 & .88 & -.11 \\
\hline & & $\mathbf{G}$ & -.43 & -.05 & .75 & .04 & -.33 & -.27 & .04 & .68 \\
\hline
\end{tabular}

